\title{
Marketing and Business Analysis in the Era of Big Data
}

\author{
Yiying Hu \\ Major of Computer Science and Technology, School of Computer Science, Wuhan University, Wuhan, China \\ Email: huyiying@163.com
}

How to cite this paper: Hu, Y.Y. (2018) Marketing and Business Analysis in the Era of Big Data. American Journal of Industrial and Business Management, 8, 1747-1756. https://doi.org/10.4236/ajibm.2018.87117

Received: June 26, 2018

Accepted: July 22, 2018

Published: July 25, 2018

Copyright $\odot 2018$ by author and Scientific Research Publishing Inc. This work is licensed under the Creative Commons Attribution International License (CC BY 4.0).

http://creativecommons.org/licenses/by/4.0/

\section{c) (i) Open Access}

\begin{abstract}
With the development of science and technology, big data, as the most important information carrier for $\mathrm{R} \& \mathrm{D}$ in high-tech era, has obviously become the latest research and development hotspot in the field of science and technology. As the latest characteristics of the times, big data will be faced with huge challenge and cause a series of related problems for the marketing management models of major companies. This paper has studied and analyzed the effect of big data to the enterprises and gets a conclusion that if the enterprises could not realize the importance of this era and adopt specific methods, they would be lost by their competitors. This paper has also given suggestions to the government that it should seize this opportunity to fully tap the huge value of the hidden potential of big data, promote the benign development and transformation and upgrading of traditional enterprises, optimize the allocation of resources, and make enterprises develop quickly for the development of the national economy.
\end{abstract}

\section{Keywords}

Big Data Era, Marketing, Business Analysis

\section{Introduction}

The structure of this paper is organized by three parts. The first part describes the concept of big data and the main technology, and then the paper analyzes the companies' problem in dealing with this era. In the third part, this paper gives its suggestions for the companies to improve their competition in this era. The main contribution of this paper is that it gives a relatively clear picture about the problems and methods of companies in the big data era. The main limitation of this paper is that it does not consider the condition of multinational enterprises and only focuses on the companies in China. 


\subsection{Big Data Concept}

The broad definition of big data refers to the collection composed of a large amount of data with a complex structure and numerous types which is based on the data processing and application model as well as the resources and service capabilities through data sharing and cross forming. The concept of big data has different definitions in different fields. The research institutions believe that big data is an information asset, with strong production capabilities and application capabilities, rapid growth, and many types; while the IT industry believe that big data is capable of being quantitative, diversified, and fast; some companies have proposed specific definitions. They believe that big data is not limited to capacity. More importantly, a large number of data produced through various channels are applied to the new data theoretical analysis and processing. The data collection, storage, analysis and utilization provide an important basis for the government's major decision-making and enterprise management which improves the effective implementation of the management model and increases the profit and income of the enterprise [1]. The following table is taken as an example. By comparing the status quo of the application of big data in several enterprises, the results are as Table 1 .

As showed in Table 1, the intelligent manufacturing has enjoyed a fast development in the last three years. At the same time, the financial industry, E-commerce and public management also see a big growth in big data usage, which show a new era named big data.

\subsection{Big Data Research Analysis}

Although there is not a unified standard for the definition of big data at present, this does not affect our in-depth research on big data. Nowadays, in order to enable big data to better integrate into our lives to make the most of its value, large enterprises at home and abroad and the IT industry attach great importance to the research and application of big data. Currently, big data has generated greater value in the Internet, finance, transportation, communications, enterprise development, and biomedical industries. However, China's research on big data is still at its beginning and lags behind foreign countries. Next, we will analyze the investment structure of China's big data IT application industry, as shown in Figure 1 and Figure 2.

In May 2012, an academic discussion was held in Fragrance Hill on the topic of "Big Data Science Project-an Emerging Cross-discipline". The majority of

Table 1. Industry proportion change (data from China national bureau of statistics).

\begin{tabular}{cccc}
\hline & Proportion in 2015 & Proportion in 2016 & Proportion in 2017 \\
\hline Intelligent manufacturing & $23.5 \%$ & $48.3 \%$ & $73.4 \%$ \\
Financial an securities & $8.99 \%$ & $34.7 \%$ & $65.3 \%$ \\
E-commerce & $20.1 \%$ & $45.43 \%$ & $83.83 \%$ \\
E-government & $7.78 \%$ & $23.67 \%$ & $69.65 \%$ \\
\hline
\end{tabular}




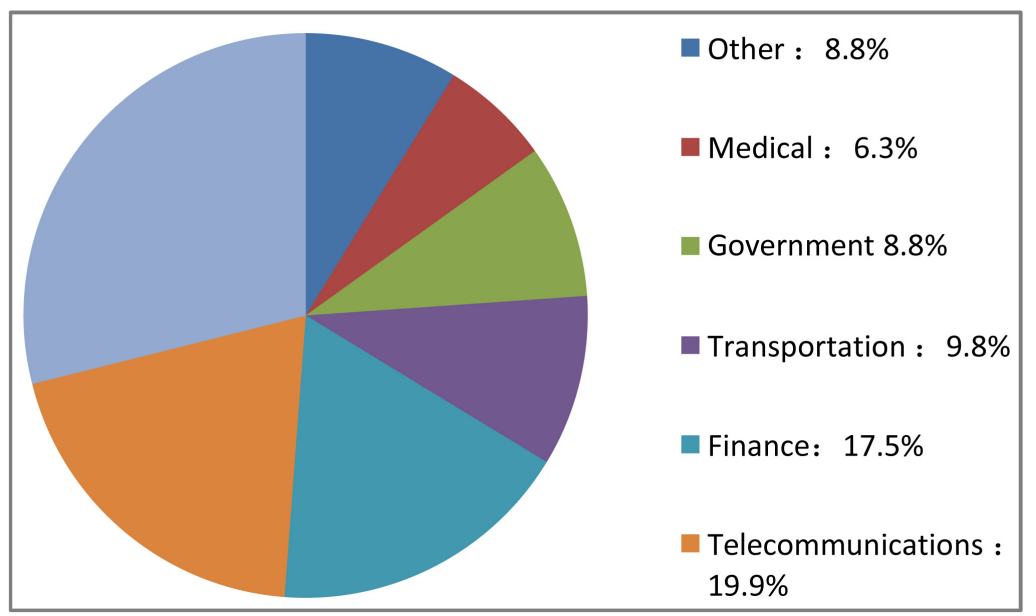

Figure 1. Big data IT application industry investment structure (data from China national bureau of statistics).

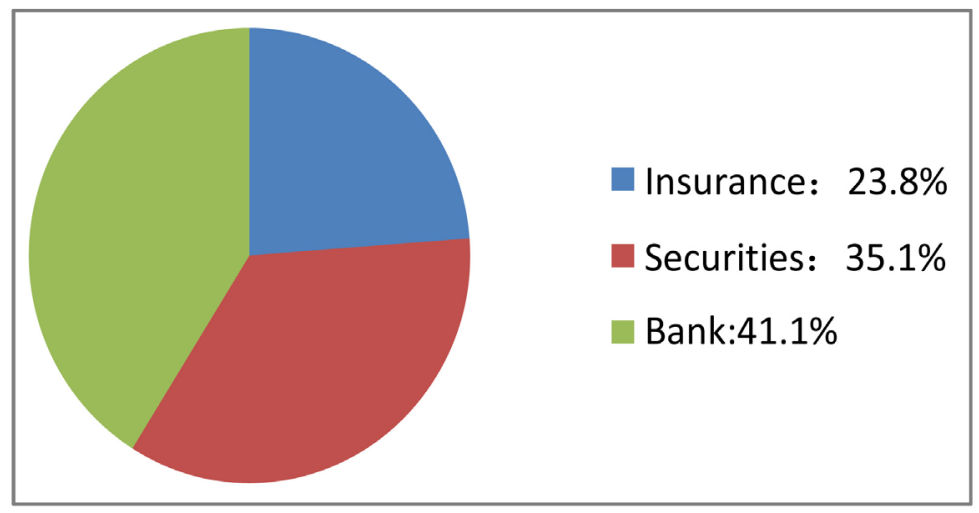

Figure 2. Investment structure of big data application in China's financial industry (data from China national bureau of statistics).

domestic outstanding research scholars conducted preliminary analysis and research on big data. In June of the same year, the China Computer Society Youth Computer Science and Technology Forum held an academic study on the theme of "Big Data Age, Inspires the Future" and conducted a in-depth exploration and discussion on the preliminary research of big data, mainly focusing on technology mining, security, and platform technology development and theoretical applications [2]. By analyzing, extracting, and integrating data, a fast, convenient and efficient big data sharing platform was constructed. Through the understanding of the specific needs of users for scientific planning and rectification, there will be more comfortable and convenient experience in use. The current source of users' access to big data is mainly through search engine. Search engines in China mainly include Baidu, China Search, Google, Netease, Sohu, Sogou, Yahoo, Sina, etc., and users purposefully choose the right one based on unique features of different search engines, make the best of vitality of the data, ensure the smooth flow of data, and demonstrate the maximum use value of the data itself, as shown in Figure 3. 


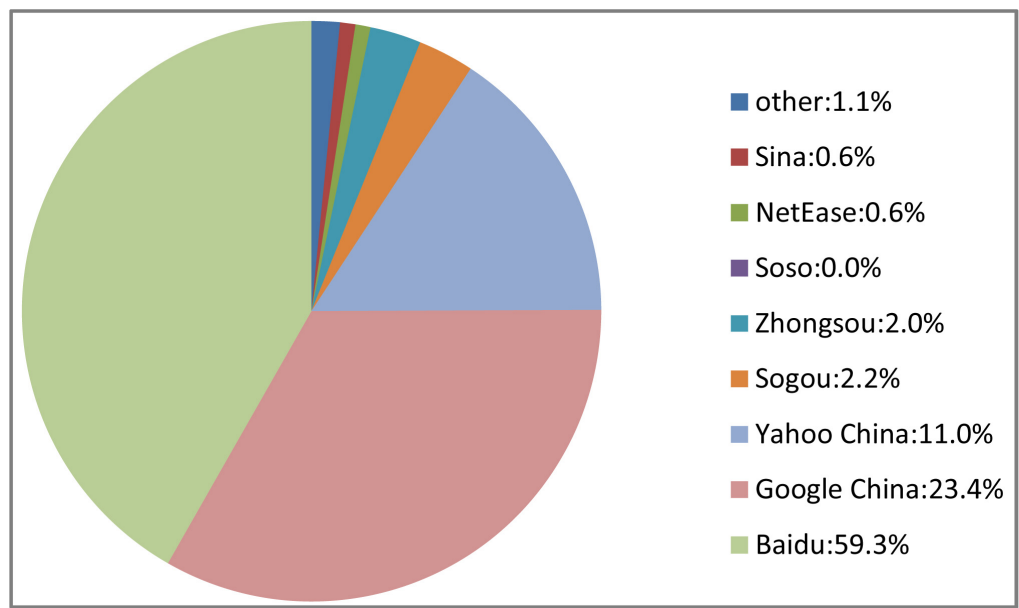

Figure 3. Market share of search engine in China in 2007 (data from China national bureau of statistics).

\section{The Practical Problems Faced by Corporate Management in the Era of Big Data}

\subsection{Insufficient Enterprise Intelligent Management}

The basic meaning of the lack of enterprise intelligence mainly refers to that in the process of enterprise operation, deficiency is detected through reflecting and supporting system, thus a series of concrete solutions is conducted to help the establishment and implementation of business policy, and the enterprise optimization management is effectively carried out through high-tech intelligent technology. In the current business management model, the high and new technology needed in the current high-tech era is not effectively adopted. Besides, the ideological management model continues to age, the manager's idea is too rigid. In the application of big data, consumers' consumption habits and consumption preferences can not be timely received with inaccurate positioning of consumers and satisfying customer services. For the enterprise marketing activities, once the problem of consumer consumption can not be solved accurately, it will greatly reduce the attention and demand of consumers, thus reduce the operating profit brought by the consumption and greatly decrease the economic benefits of the enterprise. The network social ability of the internal staff of the enterprise is too weak, the ability of ideological innovation is not enough, and the ability to solve the problem is insufficient which makes it difficult for employees to get along with each other in the process of enterprise production, leading to the gap among people. Thus, it is difficult for enterprises to form a unified ideological management mode, which adds difficulty to enterprise's ideological management innovation.

\subsection{Corporate Managers Pay Insufficient Attention to the Value of Big Data in Business}

At present, big data is developing rapidly in the era of high-tech development, but people's understanding of large data is not comprehensive enough to inte- 
grate well big data into enterprise management marketing. Big data has not been completely universalized. Many enterprise managers still focus their business management on the traditional marketing model. When the emergence of big data collides with the traditional management marketing model, the traditional enterprise marketing model suffers from great pressure. Because of the lack of thorough understanding of big data and the neglect of value of big data in business, managers blindly deny the importance of large data, and still put the traditional marketing management model in the first place. Superficially, enterprises have acquired large amounts of data and used big data in the management mode of enterprises. But in fact, the enterprise managers do not fully grasp the significance of big data, only apply some macro data to management and ignore the micro data which will reduce the possibility to discover the enterprise problem, and cause the disadvantages for enterprise to carry out the marketing activities with the incomplete problem solving.

\subsection{The Great Lack of Professional Talents}

In the fast-developing high-teach era, big data technology has developed rapidly. All industries need professional talents to improve technology informatization, marketing, and enterprise management. In the era of big data, all kinds of data converge to form a more reasonable and professional technical means. The data management and analysis is not the primary task of information, but the power of the team [3]. In the adjustment process of big data resources, it is necessary to integrate the ability of understanding information technology, controlling the information exchange law, analyzing and processing data. Take the essence and go to the dregs to create a new idea of data analysis, for which, a large number of high-tech personnel is needed to suggest professional solutions for marketing, enterprise operation and management. However, most of the enterprises have not discovered such practical problems which require corporate managers to have the correct values, to view the issues comprehensively, and to fundamentally deal with the shortage of professional talents.

\section{How Should the Enterprise Management Model Adapt to the Era of Big Data?}

\subsection{Marketing Precision}

In the era of big data, corporate marketers can understand consumers' needs through multiple aspects and analyze consumer's consumption concepts, preferences, and habits, such as web browsing records, information search, and product purchase frequency to carry out marketing analysis, positioning, excavate new product combinations, and formulate personalized marketing plans and business decisions. Tailor-made plans can be formulated for personalized consumers. It is necessary to provide personalized service and understand consumer needs in depth to more accurately meet customer needs, increase consumer satisfaction and consumption, and effectively carry out marketing activi- 
ties to increase enterprise marketing benefits.

For the steel industry, the shift from database to business intelligence is to give new features and meanings to big data. Through the integration of data analysis, the extraction of valuable information, and effective data processing, the data can be finally applied to the intelligent business system, which can provide important basis for the enterprise to carry out specific transactions, and bring great benefits to the enterprise marketing management, as shown in Figure 4.

Through systematization and precision of enterprise cost management, it will strengthen the cost control of the company's production environment, reduce cost consumption and production losses, improve product quality and assessment standards, strengthen staff capabilities, and enhance financial system management [4]. Through analysis and research on the multi-system management, it is possible to accurately discover problems and quickly create the best solution, as shown in Figure 5.

Formula:

- Consumer surplus = the amount of money to be paid - the amount of money actually paid.

- The amount of money willing to pay $=$ unit price willing to pay $\times$ number of purchases.

- The amount of money actually paid $=$ the actual unit price paid $\times$ purchase quantity.

- Consumer surplus acquisition rate = consumer surplus obtained by the enterprise/total consumer surplus.

- Any price between P-P's is the unit price willing to pay, $\mathrm{P}$ is the actual unit price paid by the consumer, which is the firm's pricing; $Q$ is the purchase quantity, and $\mathrm{D}$ is the demand curve. The area of the pentagonal is the amount consumers tend to pay.

\subsection{Transform the Traditional Marketing Strategy}

Different consumers have different consumption purposes with various consumer

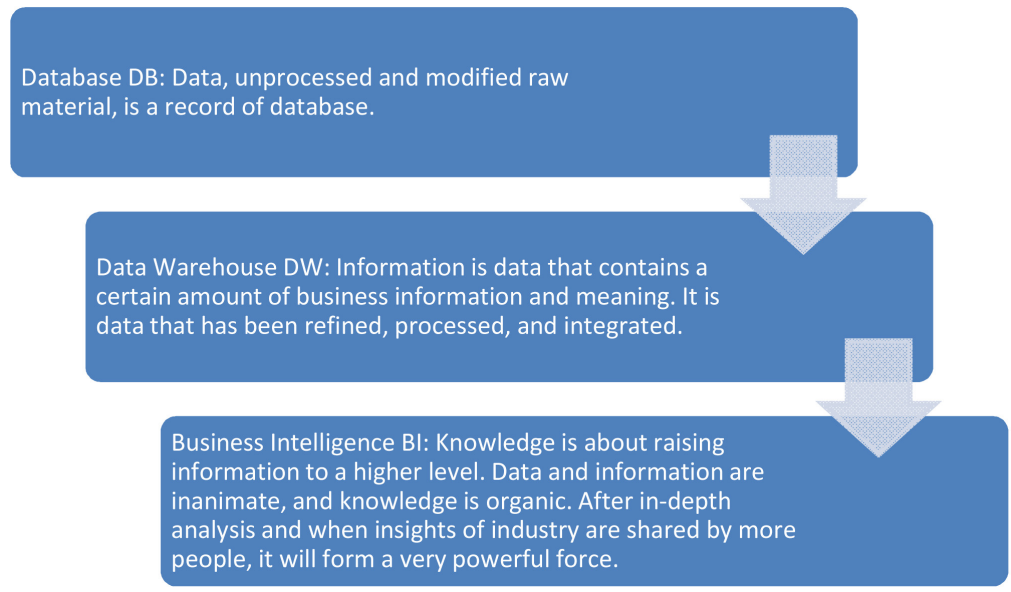

Figure 4. From database to business intelligence. 


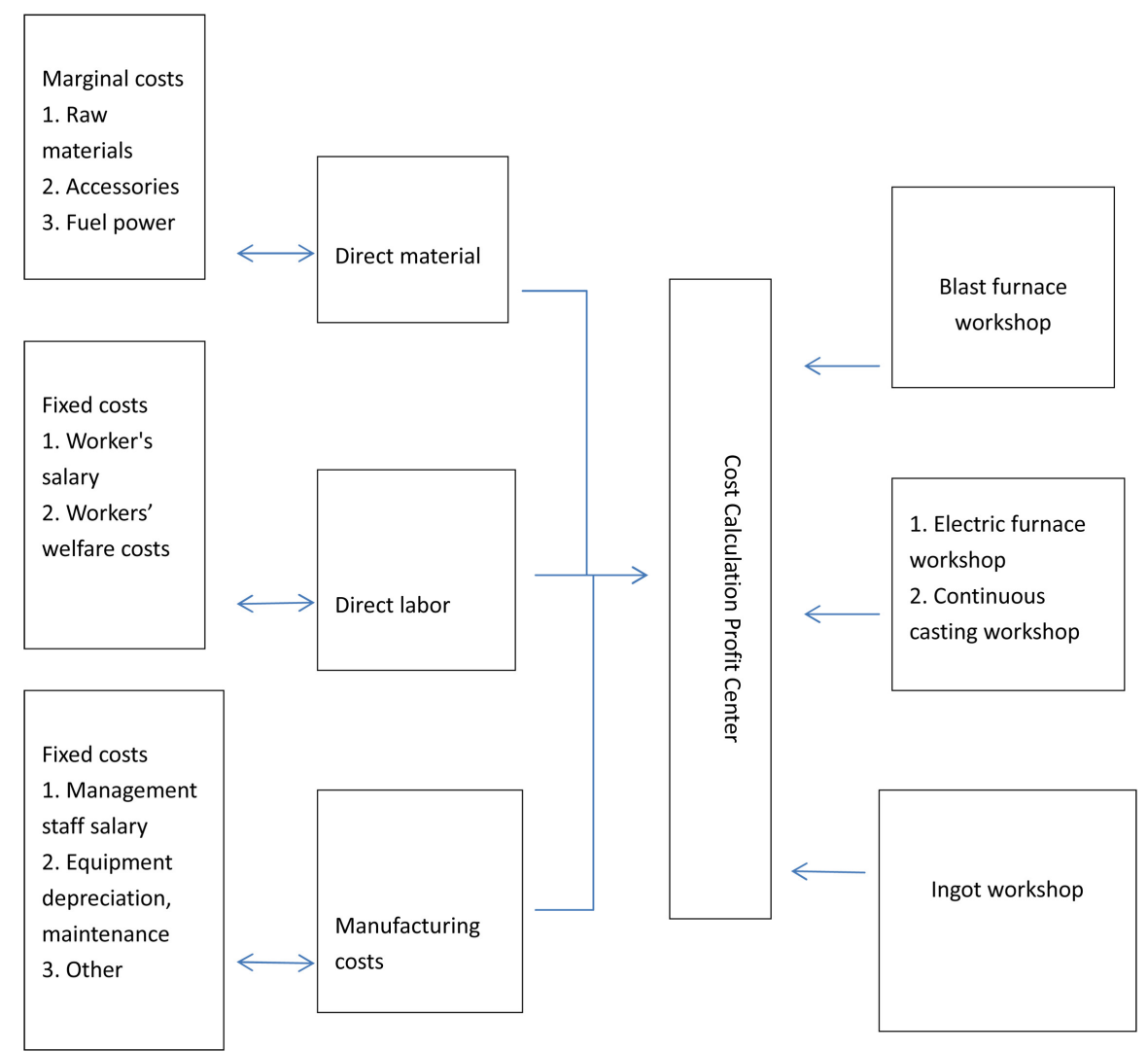

Figure 5. Production cost calculation model for iron and steel enterprises.

demands. Companies should develop individualized marketing plans for different needs. According to the differences in specific consumer needs, it is significant to deeply understand the inner thoughts of consumers and analyze consumer preferences. Through specific feedback from customers, forecast consumer's future consumer behavior, and take targeted solutions. Provide accurate and high-quality service to old customers, retain old customers, attract new customers, and establish long-term and good cooperative relationships [5]. Through specific data research and analysis, discover potential consumers. The use of big data has replaced the traditional corporate marketing strategy with an innovative management model, and has have precise, personalized and diversified marketing effect on the marketing management strategy of the company.

\subsubsection{Change Immobilization of Price}

The pricing method of the product is gradually changed from the production cost based pricing method to customer based pricing method by collecting specific consumption data collected through big data technology for effective analysis and research, fully understanding the consumer acceptance of product prices, and estimating the ideal price for the consumers.

\subsubsection{Increase Consumption Channels}

With the progress of the times, the development of science and technology, and the rapid development of Internet technology, the online sales model has gradu- 
ally come into being, and payment via WeChat, Alipay and so on has brought convenience to consumers [6]. In addition to the traditional B2B, B2C, and C2C models in recent years, $\mathrm{O} 2 \mathrm{O}$ refers to the process to promote the offline consumption through online selling, purchasing or booking; to provide consumers with accurate information related to catering, fitness, entertainment through discount, service reservations, information supplying. At present, this business model has been integrated into life and has become an indispensable part. The following figure shows the comparison of online and offline sales of a certain product.

According to Table 2, it can be effectively seen that with the passage of time and the development of Internet technology, the proportion of online sales has gradually increased, so we should continue to pay more attention to increasing consumption channels and make commercial reform and innovation of enterprise marketing.

\subsubsection{Cross-Selling of Products}

Through a detailed analysis of consumer spending, it is found that when consumers purchase a product, they choose similar products or different products at the same time. For example, L'OREAL, the world's largest cosmetics company, analyzed the purchasing behavior of consumers and found that most female customers would buy the same series of isolation, BB and moisturizing products after buying sunscreen. In this way, bundle sales are used to improve the sales. It is the application of big data technology that helps L'OREAL make more marketing profit.

\subsubsection{Strengthen the Intelligent Marketing Model}

The development of an enterprise depends on whether the management mode of the enterprise can keep pace with the progress of the times and whether the management mode is intelligent. Yonghong Data Mart is software for data storage and data processing developed based on its own technology. It provides two solutions for customers, a local mode and a MPP mode; based on the different data magnitude that customer needs to deal with, the different architecture of the IT system and the different storage systems. When the amount of data to be processed is below the terabyte level, users are advised to select the local mode. When faced with a heterogeneous database storage system, and when the amount of data to be processed is above the TB level and the PB level, the parallel processing mode of the distributed architecture is more suitable. In the era of big data, facing a series of intelligent issues, companies must establish a sound

Table 2. Company profit change (data from china national bureau of statistics).

\begin{tabular}{cccc}
\hline & Profit ratio in 2015 & Profit ratio in 2016 & Profit ratio in 2017 \\
\hline Offline & $60 \%$ & $55 \%$ & $45 \%$ \\
Jingdong & $10 \%$ & $20 \%$ & $25 \%$ \\
Taobao & $30 \%$ & $20 \%$ & $30 \%$ \\
\hline
\end{tabular}


information foundation, fully implement intelligent office, and create a more secure security system, so that accurate data analysis and processing can be achieved. With the construction of technical talents and introduction of high-tech personnel, the company is able to improve the level of knowledge management of staff, and achieve all-round intelligent management so that the traditional management model of enterprises can be gradually transformed into the innovation model.

\subsubsection{Improve the Quality of Management Team}

In order to improve the overall quality of the management team, enterprises must improve their professional qualities, test personal qualities in all aspects, and constantly improve their own deficiencies. Through organizing some activities, they can recognize their own deficiencies in the competition and make improvement. Companies can use rewards and penalties to increase the enthusiasm of their staff and stimulate their own creativity. Only by continuously improving the personal professionalism can the cooperation among the team members be better. Do a good job of management at each stage and improve the overall quality of the team [7].

\subsubsection{Establish an Employee Relationship Network}

In the traditional management model, the employees' specific ideas are not fully understood. Because the staff has little social contact with the network, employees have little interaction with each other. If an enterprise wants to continue its development, it should establish a perfect relationship network within the enterprise. Enterprises should take this social network as the management focus. Only in this way can they effectively innovate the management model and achieve a substantial increase in corporate profits.

\section{Conclusions}

Under the current social situation, science and technology continue to make progress, and the era of Internet data has developed rapidly. The arrival of the era of big data has brought about tremendous changes in everyone's lives, and has virtually integrated into our lives and businesses. Big data plays a major role in the future development of the enterprise. It is crucial to face up to the opportunities and challenges that big data brings to the enterprise. Through in-depth analysis and research of data, its potential value can be dug deep. Through the analysis of consumer psychology, the company can grasp the rules of market development. According to the different market development, enterprises can formulate a series of targeted marketing mix strategies. Through the innovation of institutional management mode, it is convenient for enterprises to make marketing strategies and carry out innovative management and marketing activities. Through in-depth analysis and research of data-based theory and technology, it provides enterprises with powerful data support. Strengthen the relationship network of data, and connect the enterprise and various industries together 
through big data, which is beneficial to improve the enterprise management system, and make the emerging industry become an important new economic growth point in China to promote the innovation and transformation of traditional industry and industrial innovation.

At present, it is critical for both government and companies to establish and improve the national and company's big data resource pool. The government should seize this opportunity to fully tap the huge value of the hidden potential of big data, promote the benign development and transformation and upgrading of traditional enterprises, optimize the allocation of resources, and make enterprises develop quickly for the development of the national economy. The company also needs to fully use resources of the government and pay more attention to the usage and technology of big data, which would keep them a good competition advantage in the future.

\section{Conflicts of Interest}

The authors declare no conflicts of interest regarding the publication of this paper.

\section{References}

[1] Lin, Y.Q. (2017) On Marketing Transformation in the Era of Big Data. Modern Marketing, 8, 62 .

[2] Wang, X.Y. (2017) On the Value, Foundation and Direction of Marketing Innovation Research in the Era of Big Data. Communication World, 10, 167-168.

[3] Li, G.B. (2016) Talking about the Innovation of Enterprise Management Mode Under the Big Data Environment. Enterprise Reform and Management, 16, 6.

[4] Zhang, S.Q. (2014) On the Challenges and Strategies of Enterprise Marketing in the Era of Contemporary Formal Logic. Development of Contemporary Formal Logic to Promote the Revitalization of New Thinking in Guizhou-Seize the Opportunity and Move into the "Big Data" Era of Academic Salon. Guizhou Science and Technology Association, 5.

[5] Mao, J. (2017) Research on Precision Marketing Strategy of Yunnan Branch of China Construction Bank in the Era of Big Data. Yunnan University of Finance and Economics, Kunming.

[6] Guo, H.Y. (2017) Application of Big Data in Financial Risk Control and Precision Marketing and Big Data Project Risk Research. Shandong University, Jinan.

[7] Liu, C.J., Hu, T. and Zhao, H.Y. (2017) Analysis of the Environment and Countermeasures of Retailing in the Era of Big Data. Contemporary Economy, 31, 76-77. 